\title{
Mechanochemical Synthesis of Rosuvastatin Intermediates by Liquid-Assisted Wittig Reaction
}

\author{
Jianbo Yan1, Chengjun Jiang2* \\ ${ }^{1}$ Zhejiang Lepu Pharmaceutical Co., Ltd., Taizhou, China \\ ${ }^{2}$ School of Biological and Chemical Engineering, Zhejiang University of Science and Technology, Hangzhou, China \\ Email: ${ }^{*}$ jcj312@zust.edu.cn
}

How to cite this paper: Yan, J.B. and Jiang, C.J. (2020) Mechanochemical Synthesis of Rosuvastatin Intermediates by Liquid-Assisted Wittig Reaction. Open Access Library Journal, 7: e6421.

https://doi.org/10.4236/oalib.1106421

Received: May 13, 2020

Accepted: June 26, 2020

Published: June 29, 2020

Copyright $\odot 2020$ by author(s) and Open Access Library Inc.

This work is licensed under the Creative Commons Attribution International License (CC BY 4.0).

http://creativecommons.org/licenses/by/4.0/ (c) (i) Open Access

\begin{abstract}
Liquid-assisted Wittig reaction is used to synthesis of Rosuvastatin intermediates (1,3-Dioxane-4-acetic acid, (4R,6S)-6-[(1E)-2-[4-(4-fluorophenyl)-6(1-methylethyl)-2-[methyl(methylsulfonyl)amino]-5-pyrimidinyl]ethenyl]-2, 2-dimethyl-1,1-dimethylethyl ester). Evaluate the reaction using common green chemistry metrics: environmental factor (E-factor), and systematic investigation of the reaction has been made in order to study the various factors affecting the reaction. The E-factor of Liquid-assisted Wittig reaction is about a quarter of the traditional method. Under optimal conditions, the conversion rate can reach 99.2 and the $\mathrm{E}: \mathrm{Z}$ ratio can reach 76:24.
\end{abstract}

\section{Subject Areas}

Chemical Engineering \& Technology

\section{Keywords}

Wittig Reaction, Synthesis, Rosuvastatin Intermediates

\section{Introduction}

The Wittig reaction is one of the most useful reactions for the synthesis of olefins [1]. In the last few decades, this reaction has been extensively studied and employed in synthesis even on an industrial scale [2]. Rosuvastatin calcium, chemically described as bis(3R,5S,E)-7-(4-(4-fluorophenyl)-6-isopropyl-2-(Nmethylmethylsulfonamido)pyrimidin-5-yl)-3,5-dihydroxyhept-6-enoic acid calcium salt, is a synthetic lipid-lowering agent that acts as an inhibitor of 3-hydroxy-3-methylglutaryl-coenzyme (HMG-CoA reductase inhibitor). 
HMG-CoA reductase inhibitors are commonly referred to as statins. Statins are therapeutically effective drugs used for reducing low density lipoprotein (LDL) particle concentration in the blood stream of patients at risk for cardiovascular disease [3]. Therefore, rosuvastatin calcium is used in the treatment of hypercholesterolemia and mixed dyslipidemia [4]. 1,3-Dioxane-4-acetic acid, $(4 R, 6 S)$ 6-[(1E)-2-[4-(4-fluorophenyl)-6-(1-methylethyl)-2-[methyl(methylsulfonyl)ami no]-5-pyrimidinyl]ethenyl]-2,2-dimethyl-1,1-dimethylethyl ester $\left(\mathrm{R}_{1}\right)$, is a possible key intermediate in the synthesis of rosuvastatin and its pharmaceutically acceptable salts [5]. Rosuvastatin has evoked much interest of many research groups as a synthetic target. At present, there are two main synthetic processes in industry. One is the Wittig reaction (Figure 1).

This reaction led to formation of the rosuvastatin precursor, which was subsequently converted into rosuvastatin calcium followed by well-established synthetic operations. [[4-(4-fluorophenyl)-6-(1-methylethyl)-2-[methyl (methylsulfonyl)amino]-5 pyrimidinyl]methyl] triphenyl-bromide (Z9) was then coupled with Tert-butyl 2-[(4R,6S)-6-Formyl-2,2-dimethyl-1,3-dioxan-4-yl) acetate (D7) under Wittig olefination conditions (potassium carbonate as catalyst in dimethyl sulfoxide (DMSO) solvent) [6] [7] [8] [9]. However, the biggest problem with this route is highly environmental pollution. Using DMSO as solvent was very difficult to recycle, along with the low yield. We wondered whether it would be possible to develop an organic reaction in the ball mill to achieve a process comparable to conventional solution-phase reaction.

\section{General Methods}

\subsection{Experimental Materials}

D7, Z9 were gifted from Lepu Pharmaceuticals and used without further purification. All solvents and reagents were obtained from Energy Chemical and used without further purification.

\subsection{Mechanochemical Procedure for the Synthesis of $\mathbf{R}_{1}$}

Mechanochemical Wittig reaction in a customized stainless steel vial $(3.0 \mathrm{~mL}$ volume) was carried out by adding $1 \mathrm{mmol} \mathrm{D7,} 1 \mathrm{mmol} \mathrm{Z9}$ and $1.3 \mathrm{mmol}$ base. The mixture was ball-milled for 16 hrs. For liquid-assisted grinding experiments, $1 \mathrm{~mL}$ solvent was also added. The vial was shaked at $20 \mathrm{~Hz}$ in a Spex8000M Mixer/Mill. HPLC was performed to evaluate the composition of filtrate. Typically,

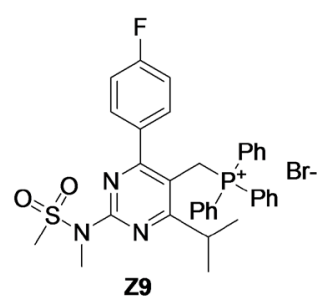

Z9

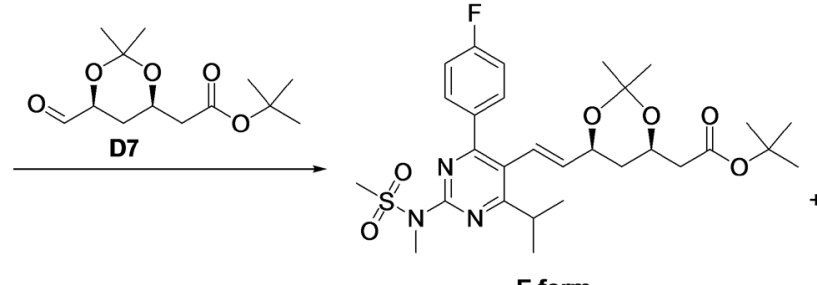

E form

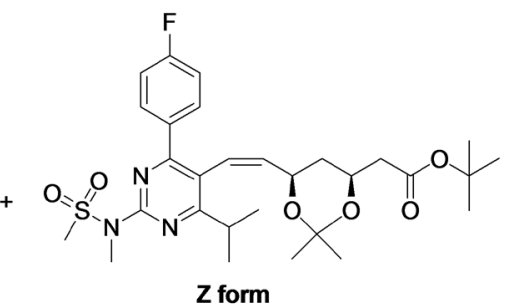

$\mathrm{Z}$ form

Figure 1. Synthesis of Rosuvastatin intermediates by liquid-assisted Wittig reaction. 
$0.670 \mathrm{~g} \mathrm{D} 7,0.258 \mathrm{~g} \mathrm{Z9}$ and $0.197 \mathrm{~g}$ 1,8-Diazabicyclo[5.4.0]undec-7-ene (DBU) were added at temperature around $25^{\circ} \mathrm{C}$, then ball-milled for $16 \mathrm{hrs}$. After the reaction was completed, $2 \mathrm{~mL} 95 \%$ ethanol was added to the solution in the reflux state. Then the temperature was lowered to $0^{\circ} \mathrm{C}-5^{\circ} \mathrm{C}$ in order to precipitate the off-white crystalline solid, which was dried in an oven at temperature $55^{\circ} \mathrm{C}$ to obtain about $0.4 \mathrm{~g}$ product.

\subsection{General Procedure for the Synthesis of $\mathbf{R}_{1}$}

In a $250 \mathrm{~mL}$ 4-necked round bottom flask, DMSO $(150 \mathrm{~mL})$, potassium carbonate $(33.54 \mathrm{~g}), \mathrm{Z} 9(50 \mathrm{~g})$ and $\mathrm{D} 7(20.87 \mathrm{~g})$ were added at temperature range of $25^{\circ} \mathrm{C}$ to $35^{\circ} \mathrm{C}$ under stirring with speed $250 \mathrm{rpm} / \mathrm{min}$ [10]. The reaction mixture was heated to $70^{\circ} \mathrm{C}-75^{\circ} \mathrm{C}$ for 5 to 7 hours. After completion of the reaction as determined by TLC, the reaction mixture was cooled to a temperature range of $25^{\circ} \mathrm{C}$ to $35^{\circ} \mathrm{C}$. Toluene $(250 \mathrm{~mL})$ was added for dilution of the reaction mixture and stirred for 30 minutes. The organic layer was added to water $(100 \mathrm{~mL})$ under stirring and maintained for 30 minutes. The organic layer was separated and washed with water $(2 \times 100 \mathrm{~mL})$ in the same manner as described above. The organic layer was distilled in Rotavapor bath at temperature from $50^{\circ} \mathrm{C}$ to $60^{\circ} \mathrm{C}$ under vacuum. After distillation, isopropanol $(100 \mathrm{~mL})$ was added to the residue immediately, and the mixture was maintained for 30 minutes. Then the reaction mixture was brought to a temperature range of $25^{\circ} \mathrm{C}$ to $30^{\circ} \mathrm{C}$ by circulating room-temperature water slowly. In this period, the emerging precipitate was further cooled to $10^{\circ} \mathrm{C}$ for 30 minutes, and then filtered by using filter paper. The filter cake was washed with prechilled (at temperature $10^{\circ} \mathrm{C}$ ) isopropanol $(50 \mathrm{~mL})$. The product was dried in an oven at $55^{\circ} \mathrm{C}$ until the moisture content was no more than $1 \%$. The dried product appeared as an off-white crystalline solid weighing about $45 \mathrm{~g}$.

\section{Results and Discussion}

\subsection{Solvent Effect on the Mechanochemical Witting Reaction}

To focus the study, Z9, D7 and potassium carbonate were ball-milled in a stainless-steel vial with solvents at opposite ends of the dielectric spectrum, as well as a control without any solvent (Table 1).

In general, we noticed that more polar solvents (high dielectric constants) favor $\mathrm{Z}$ selectivity and a higher overall conversion, whereas the use of less polar solvents (lower dielectric constants) favors E selectivity and a lower overall conversion. It was very exciting that in the absence of solvent, the conversion could reach $99.1 \%$, and the $\mathrm{E} / \mathrm{Z}$ ratio could achieve $70: 30$. The reason may be that $\mathrm{D} 7$ gradually turned into liquid state during the grinding process. In addition, under the grinding conditions, the longer the potassium carbonate is ground, the finer the particles, new potassium carbonate would be exposed continuously to promote the reaction. Therefore, this reaction can be performed without solvents. 
Table 1. LAG solvent effect on the mechanochemical witting reaction.

\begin{tabular}{cccc}
\hline LAG solvent & Dielectric constant & Conversion (\%) & E:Z ratio \\
\hline none & 0 & $99.1 \%$ & $70: 30$ \\
methanol & 33.6 & $98.3 \%$ & $58: 42$ \\
ethanol & 24.3 & $98.2 \%$ & $60: 40$ \\
n-hexane & 1.58 & $97.5 \%$ & $76: 24$ \\
toluene & 2.37 & $96.8 \%$ & $75: 25$ \\
Acetone & 20.7 & $99.1 \%$ & $62: 38$ \\
Tetrahydrofuran & 7.58 & $99.3 \%$ & $68: 32$ \\
\hline
\end{tabular}

\subsection{Alkali Effect on the Mechanochemical Witting Reaction}

Witting reaction's selectivity depends on a number of factors. In the presence of lithium and sodium salts, highly selective (E)-olefins were obtained [11]. The strength of bases is crucial to the reaction [12] [13]. To study the influence of bases in the ball mill, some commonly used bases were applied (Table 2).

It was surprising that the common inorganic bases, potassium hydroxide and sodium hydroxide, played a good role in the solvent-free process with high yield (entries 1 - 2). From the perspective of conversion, potassium carbonate was much better than sodium carbonate. The main reason is that the alkalinity of potassium carbonate is stronger than that of sodium carbonate (entries 3 - 4). However, the reaction exhibited worse performance when the stronger bases such as $\mathrm{CH}_{3} \mathrm{CH}_{2} \mathrm{OK}$ or $\mathrm{CH}_{3} \mathrm{CH}_{2} \mathrm{ONa}$ were used (entries 5 - 6). Furthermore, the organic base $\mathrm{DBU}$ initiated the reaction well under the conditions (entries $7, \mathrm{pKa}$ for $\mathrm{DBU}=24.13)$ [14]. Wittig reaction by using DBU as the base is a good choice, so DBU was chosen for the following optimization. The acquired data confirmed the solid-state character of the events leading to the mechanochemical generation of phosphorus ylides [15] [16] [17], which include: (i) breaking the crystal lattice of a phosphonium compound and the formation of an amorphous phase; (ii) deprotonation of an amorphous phosphonium salt by DBU in a homogeneous solid-state reaction.

\subsection{Evaluate the Reaction Using E-Factor}

E-factor is an important index to evaluate the environmental impact of a reaction [18]. It enables us to estimate the amount of waste that could be generated per kilogram of product produced. The higher the E-factor value, the more waste will be generated.

$$
\text { E-factor }=\frac{\operatorname{mass}(\text { waste })}{\operatorname{mass}(\text { product })}
$$

where mass (waste) and mass (product) represent the amounts of waste and product generated in the same weight unit. Unlike the atom economy, the waste accounts for all nonrecyclable postreaction components including unreacted starting materials, byproducts and solvents. For example, the oil industrial 
processes have a lower E-factor because they are highly optimized for their tasks, and various products generated from the refinery are utilized very efficiently, which minimizes deposals. Higher value products such as pharmaceuticals always have a higher E-factor due to the multistep synthesis procedures. The essence of green chemistry is to reduce the use and generation of hazardous substances through careful design; E-factor serves as a parameter for the chemists to achieve waste reduction that is based on the outcome of reaction.

The E-factors for both procedures were calculated using Equation (1) and shown in Table 3. Although solvents could be reduced to improve the E-factor value for the general procedure, however, the solvent cannot be recycled in many cases. On the contrary, the mechanochemical route achieved the lower E-factor because of the higher production volume of the product at the rarely using a highly toxic solvent or reagent. It is important to realize that the E-factor is often strongly dictated by the amount of solvent used relative to the production. This is consistent with the practice that solvents account for the highest amount of waste produced in the chemical industry.

\section{Conclusion}

In summary, a novel and convenient method for the synthesis of Rosuvastatin

Table 2. Screening of bases for the formation of $R_{1}$.

\begin{tabular}{cccc}
\hline Entry & Base & Conversion $(\%)$ & E:Z ratio \\
\hline 1 & $\mathrm{KOH}$ & 98.6 & $67: 33$ \\
2 & $\mathrm{NaOH}$ & 98.7 & $68: 32$ \\
3 & $\mathrm{~K}_{2} \mathrm{CO}_{3}$ & 99.1 & $70: 30$ \\
4 & $\mathrm{Na}_{2} \mathrm{CO}_{3}$ & 75.6 & $75: 25$ \\
5 & $\mathrm{CH}_{3} \mathrm{CH}_{2} \mathrm{OK}$ & 87.6 & $63: 27$ \\
6 & $\mathrm{CH}_{3} \mathrm{CH}_{2} \mathrm{ONa}$ & 86.7 & $65: 35$ \\
7 & $\mathrm{DBU}$ & 99.2 & $76: 24$ \\
\hline
\end{tabular}

Table 3. Comparison of E-factor for mechanochemical and general procedure.

\begin{tabular}{ccc}
\hline & Mechanochemical & General procedure \\
\hline Solvent & none & $\begin{array}{c}\text { DMSO }(150 \mathrm{~mL}) \text {, Toluene }(250 \mathrm{~mL}), \\
\text { isopropanol }(150 \mathrm{~mL}) \text {, water }(300 \mathrm{~mL})\end{array}$ \\
Starting materials & $\mathrm{Z} 9(0.258 \mathrm{~g})$ and D7 $(0.67 \mathrm{~g})$ & $\mathrm{Z} 9(50 \mathrm{~g})$ and $\mathrm{D} 7(20.87 \mathrm{~g})$ \\
Nonrecycled solvent waste & $0.2 \mathrm{~mL}$ Ethanol & $55 \mathrm{~mL}$ organic solvent \\
Cat. or reagent & $\mathrm{DBU}(0.197 \mathrm{~g})$ & Potassium carbonate $(33.54 \mathrm{~g})$ \\
Waste & Ethanol, $\mathrm{DBU}, \mathrm{PPh}_{3} \mathrm{O}$ & water, $\mathrm{KBr}, \mathrm{PPh}_{3} \mathrm{O}$ \\
$\mathrm{R}_{1}$ & $0.4 \mathrm{~g}$ & $45.0 \mathrm{~g}$ \\
E-factor (dimensionless) & $\sim 2.3$ & $\sim 9.2$ \\
& Solvent recovery is calculated as $90 \%$ & \\
& &
\end{tabular}


intermediates $R_{1}$ in a ball mill had been developed. A series of bases were applied to afford the product with good yield. Simplicity of the reaction, such as solvent-free condition, fast reaction time and its potential application, promoted us to conclude that the ball mill procedure is a significantly improved version of the described reaction.

\section{Acknowledgements}

We gratefully acknowledge support from Zhejiang public welfare technology research plan (LGJ20B060001).

\section{Conflicts of Interest}

The authors declare no conflicts of interest regarding the publication of this paper.

\section{References}

[1] Byrnea, P.A. and Gilheany, D.G. (2013) The Modern Interpretation of the Wittig Reaction Mechanism. Chemical Society Reviews, 42, 6670. https://doi.org/10.1039/c3cs60105f

[2] Hoffmann, M., Deshmukh, S. and Werner, T. (2015) Scope and Limitation of the Microwave-Assisted Catalytic Wittig Reaction. European Journal of Organic Chemistry, 20, 4532-4543. https://doi.org/10.1002/ejoc.201500310

[3] Davidson, M.H. and Robinson, J.G. (2006) Lipid-Lowering Effects of Statins: A Comparative Review. Expert Opinion on Pharmacotherapy, 7, 1701-1714. https://doi.org/10.1517/14656566.7.13.1701

[4] Dogan, S., Duivenvoorden, R., Grobbee, D.E., et al. (2010) Ultrasound Protocols to Measure Carotid Intima-Media Thickness in Trials; Comparison of Reproducibility, Rate of Progression, and Effect of Intervention in Subjects with Familial Hypercholesterolemia and Subjects with Mixed Dyslipidemia. Annals of Medicine, 42, 447-464. https://doi.org/10.3109/07853890.2010.499132

[5] Casar, Z., Steinbücher, M. and Kosmrlj, J. (2010) Lactone Pathway to Statins Utilizing the Wittig Reaction. The Synthesis of Rosuvastatin. Journal of Organic Chemistry, 75, 6681-6684.

[6] Deshpande, P.B. (2009) Process for Preparation of Rosuvastatin, U.S. Patent 20090124803A1.

[7] Joshi, N., Bhirud, S.B. and Chandrasekhar, B. (2005) An Improved Process for Preparation of Rosuvastatin Derivatives, Useful as HMG-CoA Inhibitor. U.S. Patent 20050124639.

[8] Vempala, N., Rao, S. V., Shree, A.J. and Pradhan, B.S. (2016) An Asymmetric Synthesis of Rosuvastatin Calcium. Synthesis, 48, 4167-4174. https://doi.org/10.1055/s-0035-1562787

[9] Xiong, F.J., Wang, H.F., Yan, L.J., Han, S., Tao, Y., Wu, Y. and Chen, F.E. (2016) Stereocontrolled Synthesis of Rosuvastatin Calcium via Iodine Chloride-Induced Intramolecular Cyclization. Organic \& Biomolecular Chemistry, 14, 1363-1369. https://doi.org/10.1039/C5OB02245B

[10] Gudipati, S., Katkam, S., Sagyam, R.R. and Kudavalli, J.S. (2007) Processes to Produce Intermediates for Rosuvastatin. U.S. Patent 7161004B2. 
[11] Uchiyama, Y., Ohtsuki, T., Murakami, R., Shibata, M. and Sugimoto, J. (2017) (E)-Selective Wittig Reactions between a Nonstabilized Phosphonium Ylide Bearing a Phosphastibatriptycene Skeleton and Benzaldehydes. European Journal of Organic Chemistry, 2017, 159-174. https://doi.org/10.1002/ejoc.201601098

[12] Valkute, T.R., Aratikatla, E.K. and Bhattacharya, A.K. (2017) Efficient Synthesis of Functionalized Olefins by Wittig Reaction Using Amberlite Resin as a Mild Base. Synthetic Communications, 47, 581-589. https://doi.org/10.1080/00397911.2016.1276191

[13] Schirmer, M.-L., Adomeit, S. and Werner, T. (2015) First Base-Free Catalytic Wittig Reaction. Organic Letters, 17, 3078-3081.

[14] Okuma, K., Sakai, O. and Shioji, K.B. (2003) Wittig Reaction by Using DBU as a Base. Bulletin of the Chemical Society of Japan, 76, 1675-1676.

https://doi.org/10.1246/bcsj.76.1675

[15] Westman, G., Wennerström, O. and Raston, I. (1993) On the Effect of Cyclodextrin on the Z/E-Selectivity of Wittig Reactions with Semistabilized Ylides. Tetrahedron, 49, 483-488. https://doi.org/10.1016/S0040-4020(01)80315-X

[16] Ward Jr., W.J. and McEwen, W.E. (1990) Metal Ion Effects in Wittig Reactions. A General Hypothesis for the Mechanism of the Wittig Reaction. The Journal of Organic Chemistry, 55, 493-500. https://doi.org/10.1021/jo00289a021

[17] Balema, V.P., Wiench, J.W., Pruski, M. and Pecharsky, V.K. (2002) Mechanically Induced Solid-State Generation of Phosphorus Ylides and the Solvent-Free Wittig Reaction. Journal of the American Chemical Society, 124, 6244-6245. https://doi.org/10.1021/ja017908p

[18] Ribeiro, M.G.T.C., Costa, D.A. and Machado, A.A.S.C. (2010) “Green Star”: A Holistic Green Chemistry Metric for Evaluation of Teaching Laboratory Experiments. Green Chemistry Letters and Reviews, 3, 149-159. https://doi.org/10.1080/17518251003623376 